FACULDADE DE CIÊNCIAS ECONô MICAS dA UFRGS
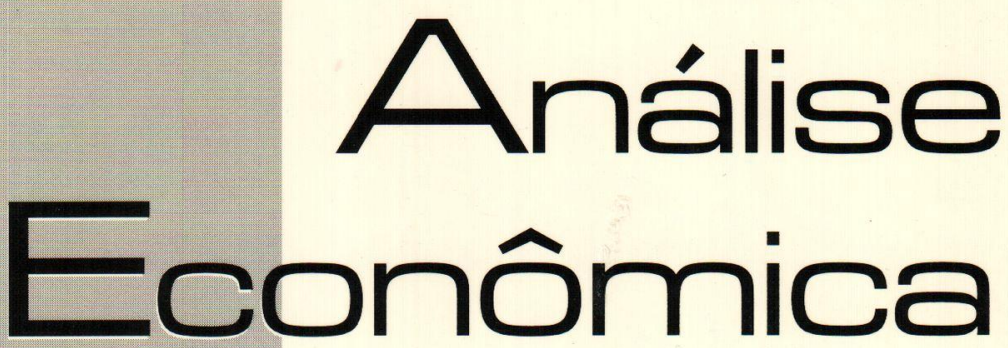

ESCOLHA DE PORTFÓLIO, INVESTIMENTO E NĀO. NEUTRALIDADE DA MOEDA

JOSÉ LUIS OREIRO

REFORMAS NA AROUITETURA FINANCEIRA INTERNACIONAL: NOVIDADES NO FRONT? ANDRÉ MOREIRA CUNHA

MERCOSUR'S CHANGE IN TRADE PATTERNS ANDRÉ FILIPE ZAGO DE AZEVEDO

O IMPACTO DA COMPOSICÃO SETORIAL, DOS FLUXOS INTRA-SETORIAIS E DA ABERTURA COMERCIAL NA PARTICIPAÇÁO DE MERCADO DAS EXPORTAÇÓES BRASILEIRAS

CLÉSIO LOURENÇO XAVIER E EMERSON FERNANDES MARÇAL

O EFEITO BALASSA-SAMUELSON E A PARIDADE DO PODER DE COMPRA NA ECONOMIA BRASILEIRA CLÁUDIO ROBERTO FÓFFANO VASCONCELOS

CICLOS Y FLUCTUACIONES FINANCIERAS: LA IRREGULAR DINÁMICA ECONÓMICA

SARY LEVY-CARCIENTE

O PENSAMENTO DE KARL POPPER: AS DIFERENTES INTERPRETACÓES DOS METODÓLOCOS DA CIENCIA ECONÓMICA

SOLANCE REGINA MARIN E RAMÓN GARCÍA FERNÁNDEZ

A EXPANSÃO DO ESCOPO TEMÁTICO DAS NEGOCIAÇÓES COLETIVAS DE TRABALHO CARLOS HENRIQUE HORN

EFEITOS DO CAPITAL SOCIAL E DO CAPITAL POLITICO NO DESENVOLVIMENTO ECONOMMICO SIMULAÇOES PARA PAISES E ESTADOS BRASILEIROS

RONALDO A. ARRAES, RICARDO CANDÉA S. BARRETO E VLADIMIR KÜHL TELES

O PROBLEMA DE RISCO MORAL NO MERCADO BRASILEIRO DE ASSISTÊNCIA MÉDICA SUPLEMENTAR LUCIANA PINTO DE ANDRADEE SABINO DA SILVA PÓRTO JÚNIOR

ANO

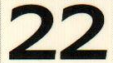

No 41

Março, 2004 
Universidade Federal do Rio Grande do Sul

Reitora: Profo. Wrana Maria Panizzi

Faculdade de Ciencias ECONOMICAS

Diretora: Prof Pedro César Dutra Fonseca

Centro de Estudos e Pesquisas Economicas

Diretor: Prof. Gentil Corazza

Departamento de Ciencias Económicas

Chefe: Prof. Ricardo Dathein

Curso de Pós-Graduação em Economia

Coordenador: Prof. Eduardo Pontual Ribeiro

Programa de Pó-Graduação em Desenvolvimento Rural

Coordenador: Prof. Jalcione Almeida

CONSElHo EDITORIAL:

Carlos G. A. Mielitz Netto (UFRGS), Eduardo A. Maldonado Filho (UFRGS), Eduardo P. Ribeiro (UFRGS), Eleutério F. S. Prado (USP), Eugênio Lagemann (UFRGS), Fernando Cardim de Carvalho (UFRJ), Fernando Ferrari Filho (UFRGS), Fernando de Holanda Barbosa (FGV/RJ), Flávio Vasconcellos Comim (UFRGS), Gentil Corazza (UFRGS), Giácomo Balbinotto Netto (UFRGS), Gustavo Franco (PUC/RJ), Jan A. Kregel (UNCTAD), João Rógério Sanson (UFSC), Joaquim Pinto de Andrade (UnB), Jorge Paulo Araújo (UFRGS), Juan H. Moldau (USP), Marcelo S. Portugal (UFRGS), Maria Alice Lahorgue (UFRGS), Paul Davidson (University of Tennessee), Paulo D. Waquil (UFRGS), Pedro C. D. Fonseca (UFRGS), Philip Arestis (Levy Economics Institut of Bard College), Roberto C. de Moraes (UFRGS), Ronald Otto Hillbrecht (UFRGS), Sabino da Silva Porto Jr. (UFRGS), Stefano Florissi (UFRGS) e Werner Baer (University of Illinois at Urbana-Champaign).

COMISSĀO EDITORIAL:

Eduardo Augusto Maldonado Filho, Fernando Ferrari Filho, Gentil Corazza, Marcelo Savino Portugal, Paulo Dabdab Waquil e Roberto Camps Moraes.

EDITOR: Prof. Fernando Ferrari Filho

Editor Adjunto: Prof. Gentil Corazza

SeCretária: Paulo Roberto Eckert

REVISÃO DE TEXTOS: Vanete Ricacheski

EdITORAÇÃo Eletrónca: Vanessa Hoffmann de Quadros

Fundador: Prof. Antônio Carlos Santos Rosa

Os materiais publicados na revista Análise Econômica são da exclusiva responsabilidade dos autores. É permitida a reprodução total ou parcial dos trabalhos, desde que seja citada a fonte. Aceita-se permuta com revistas congêneres. Aceitam-se, também, livros para divulgação, elaboração de resenhas e recensões. Toda correspondência, material para publicaçāo (vide normas na terceira capa), assinaturas e permutas devem ser dirigidos ao seguinte destinatário:

PROF. FERNANDO FERRARI FILHO Revista Análise Econômica - Av. João Pessoa, 52 CEP 90040-000 PORTO ALEGRE - RS, BRASIL Telefones: (051) 316-3513 - Fax: (051) 316-3990

Análise Econômica E-mail: rae@ufrgs.br

Ano 22, $n^{\circ} 41$, março, 2004 . Porto Alegre

Faculdade de Ciências Econômicas, UFRGS, 2004

Periodicidade semestral, março e setembro.

Tiragem: 500 exemplares

1. Teoria Econômica - Desenvolvimento Regional -

Economia Agrícola - Pesquisa Teórica e Aplicada -

Periódicos. I. Brasil

Faculdade de Ciências Econômicas,

Universidade Federal do Rio Grande do Sul. 


\title{
Efeitos do Capital Social e do Capital Políitico no Desenvolvimento Econômico: Simulações para Países e Estados Brasileiros"
}

\author{
Ronaldo A. Arraes - CAEN/UFC \\ Ricardo Candéa S. Barreto - UFC \\ Vladimir Kühl Teles - UNB
}

\begin{abstract}
Resumo: O objetivo deste trabalho é analisar e verificar empiricamente os efeitos do capital político e do capital social na elevação do nível de PIB per capita e na promoção do desenvolvimento. Neste tocante, apesar da extrema relevância de contribuição das variáveis macroeconômicas tradicionais, como tecnologia, capitais físico e humano, variáveis fiscais e monetárias, buscar-se-á também verificar a influência que as variáveis institucionais tiveram sobre estas. A hipótese que dá sustentação aos testes realizados é a de que capital social e variáveis institucionais como qualidade da burocracia, aplicação da lei; corrupção; liberdades civis; risco de conflito externo; etc. poderiam ter traçado outras trajetórias no processo de crescimento e desenvolvimento econômico. Nesse sentido, duas análises empíricas foram conduzidas: uma relaciona países, e a outra os estados brasileiros. Comprovou-se que há efeitos elásticos do capital social e do capital político sobre o processo de desenvolvimento/crescimento econômico.
\end{abstract}

Palavras-chave: Capital Social, Capital Político, Desenvolvimento Econômico.

\begin{abstract}
The objective of this paper is to verify empirically which variables possess robustness to explain variations in the per capita GDP. It is not to be pursued the contribution of traditional macroeconomic variables themselves, monetary or fiscal variables, but mainly the influence of institutional variables on them, consequently on growth. Endogenous growth theory is the background to support the empirical results. The methodological hypotheses are that social capital and institutional variables, for instance red tape bureaucracy, civil rights, corruption, law enforcement, external conflicts, etc, may hinder the economic growth process. In this reasoning, two analyses gathering worldwide countries and brazilian states were performed to test the effects of those variables on the growth path of countries and states. In conclusion, it is doubtless the significance that social and institutional variables play on determining the contemporaneous stage of economic development/growth.
\end{abstract}

Key words: Social Capital, Political Capital, Economic Development. JEL: O17, Z13.

- Os autores agradecem os comentários de um referee anônimo. 


\section{Introdução}

É consenso entre autores e instituições que as previsões das taxas de crescimento de longo prazo não são de fácil acerto. Como exemplo, pesquisadores acadêmicos proeminentes e técnicos do Banco Mundial pensavam que o estágio superior de desenvolvimento alcançado pela Coréia do Sul fosse irreal, e que a Birmânia, Sri Lanka $\mathrm{e}$ as Filipinas teriam elevado crescimento econômico. O próprio Banco Mundial documentou que vários países africanos teriam "claramente o potencial para alcançar ou mesmo superar uma taxa de crescimento anual de 7\%" (EASTERLY, 1995). Todas erradas.

Atualmente há uma forte corrente de pesquisadores, não apenas os institucionalistas, que acreditam que tais previsões estariam distorcidas porque se pensou nas origens do crescimento de longo prazo para os países errados. Houve uma certa negligência quanto à incorporação das forças sociais e institucionais no desenvolvimento econômico. Caso fosse disponível à época um índice que incorporasse fatores sócio-econômico-institucionais para guiar os pesquisadores, estes teriam errado menos nas suas previsões.

O tipo de sociedade de fato importa para o desempenho do crescimento econômico. Cole et al. (1992) enfatizam que as interações entre a organização de uma sociedade e sua performance econômica foi considerada como talvez a questão fundamental da economia política. Os arranjos sociais modernos têm sido colocados entre as precondições para o desenvolvimento econômico, tal como preconizava as Nações Unidas em suas medidas ou regras de desenvolvimento para os países sub-desenvolvidos na década de 1950 . Abramovitz e David (1996) vêem esses arranjos de potencialidades sociais englobando os atributos e qualidades dos indivíduos e organizações, que influenciam as reações das pessoas às oportunidades econômicas, como originárias das instituições políticas e sociais. $\mathrm{O}$ estado das artes neste assunto aponta para a identificação e mensuração de tais efeitos sobre o desenvolvimento econômico, em resposta ao que Abramovitz (1986, p. 307) estabelecia, à época de seu trabalho: ... nobody knows exactly its meaning (social capability) or how to measure it.

Atualmente o conceito de capital social tem estado na agenda de pesquisadores, os quais tomam como referencial o trabalho seminal de Putnam (1996). A ênfase nesta linha de pensamento tem 
sido estabelecer indicadores de "confiança" e "participação social" nos trabalhos empíricos, buscando explicar as trajetórias de desenvolvimento de países e regiões. Como ainda é emergente, a busca por influências sociais no crescimento econômico deverá gerar uma rede de possibilidades bastante vasta, fazendo com que a conexão entre dotação sociopolítica de uma sociedade e desenvolvimento econômico ainda seja um grande hiato. Neste sentido, há um grande número de pesquisas atualmente que buscam a especificação de modelos teóricos que enfatizam as deficiências de arranjos sociais e institucionais na obstrução de melhores níveis de variáveis tangíveis, como PED, capital humano, idéias e inovações tecnológicas, todas exercendo externalidades positivas para gerar rendimentos crescentes no produto per capita, ou seja, crescimento econômico.

Alguns estudos recentes sobre crescimento econômico, tais como Mauro (1995), Alesina et al., 1996, Alesina (2000), Arraes e Teles (2000), Mo (2001), vêm incluindo elementos institucionais para explicar as divergências de crescimento entre países e entre regiōes com base em modelos de crescimento endógeno. E tem sido ressaltado de forma enfática que as instituiçōes influenciam, sobremaneira, o equilíbrio de longo prazo dos países. A qualidade do governo, garantia de liberdades civis e políticas dos indivíduos, direito de propriedade, democracia, sistema legal eficaz, e outras variáveis relacionadas com os conceitos de capital social e político, são elementos que denotam um ambiente institucional confiável para a sociedade.

Um grande avanço é a idéia de que os fatores institucionais e as relações sociais de fato importam e passam agora a ser incorporados para explicar o processo de desenvolvimento de uma região. A sociedade civil com maior integração social e cooperação pode ser considerada o principal agente da modernização e da transformação socioeconômica em uma região. Exemplificando para o Brasil, apesar de poucos estudos na área, Monastério (2001) identifica que as elevadas taxas de crescimento da região norte do Rio Grande do Sul são acompanhadas de uma participação cívica maior em relação à parte sul do estado. Estudos semelhantes elaborados por Blanco (2001a; 2001b) enfocam a participação cívica nas eleições para governadores e seus efeitos sobre as despesas estaduais com conseqüências diretas para o desenvolvimento.

Assim, a hipótese principal deste trabalho é que elementos institucionais são importantes para explicar as diferenças entre paí- 
ses pobres e ricos, onde tais elementos podem ser fontes de superação do atual estágio para países e regiões pobres. Existem diferenças de objetivos e metodologias para se mensurar as instituições, todavia, é possível afirmar que não são apenas fatores de produção tangiveis que afetam o desempenho econômico dos países, regiōes ou localidades. A investigação de como o capital social e o capital político aumentam a eficiência produtiva e bem-estar da sociedade, e os efeitos da qualidade institucional na performance de economias formam o objetivo deste trabalho. A abordagem empírica fará uso de dados em painel para países e para os estados brasileiros.

\section{Aspectos da Herança Institucional}

Ao se analisar distribuição de renda entre os países nos períodos pré e pós-revolução industrial, torna-se evidente que os países, além de apresentar um nível de crescimento quase nulo, tinham um nível de renda per capita muito próximo no período pré-revolução industrial, e, no período pós-revolução industrial iniciou-se um processo de divergência entre o crescimento dos países, à medida que alguns apresentaram taxas de crescimento extremamente elevadas, enquanto outros se mantiveram estagnados.

Tal fato parece insurgir uma cisão sobre os modelos de crescimento econômico, à medida que no rol de modelos existentes, poucos são capazes de explicar ambos os momentos de crescimento analisados. Dentre tais modelos, os que parecem ficar à mercê de críticas são aqueles modelos de crescimento exógeno, gerados a partir de Solow (1956), uma vez que tais modelos são totalmente incapazes de explicitar o período de crescimento pré-revolução industrial.

Não obstante, é dentro dos modelos endógenos que encontramos a primeira orientação para explicar tal período de forma coerente, sendo esta motivada a partir de Lucas (2002), que segue o paradigma delineado por Becker et al. (1990). Assim, Lucas concentra-se em explicar as diferenças na dinâmica populacional que marcaram o período pré-revolução industrial da era moderna, o que representaria uma regra central na acumulação de capital humano, e, como conseqüência, no crescimento econômico. Tal argumentação é baseada na existência de um quantity-quality trade-off entre o 
número de crianças "produzidas" por uma família e o montante de capital humano investido em cada criança.

Por outro lado, uma explicação alternativa é apresentada por Hansen e Prescott (1998), segundo a qual a revolução industrial teria significado uma modificação no sistema de produção da economia, que antes era marcada por uma função de produção Marshaliana, e que, apenas após a revolução industrial, seria delineada pela função de produção de acordo com a modelagem de Solow. Tal explicação, mesmo reconhecendo a ineficácia do modelo exógeno em explicar o crescimento no período pré-revolução industrial, forneceria um aval para a explicação do crescimento hodierno através da abordagem exógena.

De acordo com tal linha de pesquisa, cada país "entrou" na nova era de crescimento em momentos distintos, o que representou uma defasagem entre países, de forma que aqueles que apresentaram uma estrutura institucional frágil, nesse momento histórico, demoraram algumas décadas para entrar na nova era do crescimento econômico, o que significou um distanciamento entre os PIBs per capita de países com boa e má qualidade institucional nos séculos XVIII e XIX. Entre as principais causas dessa diferença institucional encontra-se, de maneira premente, a forma de colonização. Assim sendo, países que foram colonizados, de forma a manter bases institucionais para a rápida adequação à nova era de crescimento, teriam como resposta final, atualmente, uma posição privilegiada na distribuição de renda mundial, porém, apresentando um ritmo de crescimento semelhante ao dos demais países.

Essa interpretação apresenta diferenças fundamentais do modelo de Lucas (2002), onde os patamares de crescimento econômico dos países pré e pós-revolução industrial seriam steady states do mesmo modelo de crescimento, o que significa que a qualidade institucional não determinaria apenas a data da entrada na nova era do crescimento econômico, mas apresentaria um papel fundamental na formação da base institucional dos países e, como conseqüência, do ritmo de crescimento hodierno. 


\section{Uma Proposição Histórica dos Efeitos Institucionais na Economia}

North (1990) elaborou um modelo analítico, em que as instituições formais e informais moldam e direcionam o comportamento dos agentes econômicos de modo a produzir determinados resultados em termos de ciclos de desenvolvimento econômico.

Acemoglu, Jonhson e Robinson (2000) defendem que as instituições coloniais persistiram e formaram a base das instituições atuais. $\mathrm{O}$ argumento deles descansa em três premissas:

a) a existência de políticas de colonização diferentes que criaram jogos de instituiçōes diferentes. Por exemplo, nas colônias de exploração as instituições não introduziram muita proteção para a propriedade privada, nem proveram compensaçóes para a expropriação da metrópole. De fato, o propósito principal da colônia de exploração era transferir muito dos recursos da colônia ao colonizador, com a quantia minima de investimento possível.

Ao outro extremo, muitos europeus povoaram várias colônias e reproduziram instituiçōes européias, com grande ênfase em propriedade privada. Citem-se como exemplos primários deste processo Austrália, Nova Zelândia, Canadá, e os Estados Unidos.

b) a estratégia de colonização foi influenciada pela viabilidade de determinações. Em lugares onde o ambiente de doença não era favorável à determinação européia, a formação de colônias de exploração era mais provável.

c) o estado colonial e instituiçōes persistiram até mesmo depois da independência. Neste sentido, quando as novas elites herdaram as instituições de exploração, estas não incorreram nos custos de introdução de instituições melhores e preferiram explorar as instituições de exploração existentes em beneficio próprio.

Com base nestas três premissas, o conjunto de instituições, frutos de coalizōes e arranjos do ambiente econômico, social e político que se desenvolveu nas colônias, e o conjunto de normas e regras atuais dos países definiram as regras do jogo para organizar a ação coletiva, dirigindo estruturas que permitiram a confiabilidade, evitando assim a mobilização de recursos e racionalização de sua administração. Foram usadas pelos primeiros colonos taxas de mortalidade esperada nas colônias, como um instrumento para aferir as instituições, e suas verificações levaram em consideração também controles para clima, geografia, religião, colonizador principal, re- 
cursos naturais e qualidade da terra, além do ambiente de doenças e a fragmentação etnolingüística.

Os colonos europeus poderiam ter trazido uma cultura conducente para o progresso econômico que ainda poderia ter um efeito sobre a renda per capita de hoje. Os colonos tentaram reproduzir as instituições européias com grande ênfase em propriedade privada.

Regiões onde predominou um ambiente de doenças (malária), com uma alta taxa de mortalidade, não eram favoráveis ao povoamento europeu, e/ou regiões onde ocorreu uma forte fragmentação etnolingüística, isto foi um empecilho para a reproduçāo das instituiçōes européias. Nestes casos, a formação de colônia de exploração, um sistema de mercantilismo de monopólio complexo fundamentado na estratégia de extração de recursos coloniais, era o mais provável. Assim, países subdesenvolvidos atualmente na África e América Latina não são mais pobres que outros apenas por causa de fatores geográficos ou culturais, mas também pelo pior nível de suas instituições. As instituiçōes coloniais que se adaptaram às novas situações aumentaram sua eficiência, já as instituições que não mudaram em relação às necessidades de mudanças, tendo em vista as exigências do crescimento econômico e as transformaçōes da sociedade, criaram um entrave, uma rede de instituiçōes em conflito que agem sobres os indivíduos e que se refletem nas próprias instituições através de hábitos e padrões de comportamento.

Pelo que foi discutido, cabe destacar uma variável qualitativachave de capital político como uma proxy da qualidade e ambiente institucional gerada e mantida por gerações passadas e que traz profundos efeitos na performance econômica futura - no caso a corrupção. Isto porque casos que podem implicar existência de corrupção, como tem ocorrido, recentemente, a exemplo de várias CPIs de corrupção no Congresso Nacional, é necessário observar suas conseqüências danosas tanto no campo institucional como no econômico. Além das conseqüências políticas, as de ordem econômicas são por demais severas, porquanto a corrupção também onera o crescimento econômico de uma região ao afugentar novos investimentos, ao criar incerteza quanto à apropriação dos direitos privados e sociais, processo que, em geral, vem acompanhado de estruturas institucionais ineficientes, as quais diminuem a efetividade dos investimentos públicos e privados. Em países onde é generaliza- 
da a corrupção, de cada unidade monetária investida, boa parte é desperdiçada, o que implica um investimento, de fato, menor. $\mathrm{O}$ risco político e institucional é sempre levado em conta pelos investidores internacionais e domésticos. Quando esse risco é elevado, projetos de investimentos são adiados, ou até cancelados. Em casos extremos, a corrupção crônica leva países a crises políticas permanentes que acabam em golpes de estado ou em guerras civis.

Tabela 1: Índice Anual de Corrupção para Países Selecionados 1995-2001

\begin{tabular}{|c|c|c|c|c|c|c|c|c|c|}
\hline \multirow{2}{*}{ Países } & \multicolumn{2}{|c|}{1995} & \multicolumn{2}{|c|}{2001} & \multirow{2}{*}{ Países } & \multicolumn{2}{|c|}{1995} & \multicolumn{2}{|c|}{2001} \\
\hline & Rank & Nota & Rank & Nota & & Rank & Nota & Rank & Nota \\
\hline Dinamarca & 2 & 9,32 & 2 & 9.5 & França & 17 & 7 & 23 & 67 \\
\hline Finlândia & 4 & 9,12 & 1 & 9.9 & Portugal & 21 & 5,56 & 25 & 6.3 \\
\hline Suécia & 5 & 8,87 & 6 & 9.0 & Espanha & 24 & 4,35 & 22 & 7.0 \\
\hline Canadá & 6 & 8,87 & 7 & 89 & Japão & 19 & 6,72 & 21 & 7.1 \\
\hline Holanda & 9 & 8,69 & 8 & 87 & Bélgica & 18 & 6,85 & 24 & 6.6 \\
\hline Norvega & 10 & 8,61 & 10 & 86 & África do Sul & 20 & 5,62 & 38 & 4.8 \\
\hline Suíça & 8 & 8,76 & 12 & 8.4 & Itália & 32 & 2,99 & 29 & 5.5 \\
\hline Austrália & 7 & 8,8 & 11 & 8.5 & Coréia do Sul & 25 & 4,29 & 42 & 42 \\
\hline Reino Unido & 12 & 8,57 & 13 & 83 & BRASIL & 36 & 2,7 & 46 & 4.0 \\
\hline Irlanda & II & 8,57 & 18 & 7.5 & Turquia & 27 & 4,1 & $\tilde{N}$ & $\tilde{N}$ \\
\hline Alemanha & 13 & 8,14 & $\tilde{N}$ & $\tilde{N}$ & México & 31 & 3,18 & 51 & 3.7 \\
\hline Áustria & 16 & 7,13 & 15 & 77 & Argentina & 30 & 3,24 & 57 & 3.5 \\
\hline EUA & 15 & 7,79 & 16 & 7.6 & Índia & 34 & 2,78 & 71 & 27 \\
\hline Chile & 14 & 7,94 & 18 & 7.5 & Nigéria & $\tilde{N}$ & $\cdots$ & 90 & 1.0 \\
\hline
\end{tabular}

Fonte: Transparency International, disponível on line em 2001 pela URL: www.transparency.de .

Nos últimos seis anos, no ranking de 90 naçōes, o Brasil passou da $36^{a}$ posição, em 1995, para a $46^{a}$ neste ano de $2001^{1}$. A cada ano, desde 1995, a corrupção vem aumentando no Brasil, com o país se distanciando cada vez mais daqueles dotados de elevado estoque de capital institucional como mostra a tabela 1. O Brasil vem-se posicionando como um dos países mais corruptos da América do

\footnotetext{
${ }^{1}$ Ranking feito por empresários nacionais e internacionais, numa escala de zero (mais corrupção) a dez (menos corrupção). Este indice é composto de vários outros índices feitos por empresas de consultoria que analisam riscos políticos e econômicos para investidores internacionais. Em 1998, se usou um mínimo de três e um máximo de dez destes índices para compor o ranking da Transparency International.
} 
Sul, perdendo sua posição atual para a Argentina, país que sofreu uma piora drástica no seu índice de corrupção, pois tinha uma colocação de $30^{\circ}$ em 1995 passando para $57^{\circ}$ em 2001 .

\section{Capital Social em Traço Institucional Específico}

Grotaert (1997) distinguiu capital social em duas visões: a literatura dos economistas que o identificam no papel das instituições, vigente desde da década 20 com Thorstein Veblen e Mitchell, que atualmente foi reavivado pela Nova Economia Institucional; e a literatura dos cientistas políticos, sociólogos e antropólogos que se referem ao conceito como um jogo de normas, cadeias organizações pelas quais pessoas ganham acesso a recursos e poder de decisão na formulação de políticas. E, na visão econômica, pode ser estabelecido em dois níveis: $O$ nível microeconômico, onde capital social melhora o funcionamento do mercado e o nível macroeconômico em que o seu efeito se dá por instituições niveladas, armações legais e o papel do governo na organização da produção. Uma abordagem mais genérica considera o ambiente político e social como aquele que contribua para a eficiência produtiva estática e dinâmica como componentes do capital social. Inclui, portanto, a qualidade do governo, do sistema jurídico e a garantia de liberdades políticas e civis dos indivíduos e do Estado de Direito ${ }^{2}$. Neste sentido, o capital social é quase um sinônimo de "boas" instituições (Monastério, 2000a, p. 4).

Em algum plano, a estrutura institucional é, definitivamente, importante; por exemplo, os diferentes caminhos tomados pela Coréia do Norte e do Sul, em que uma é um país estagnado sob o plano central e coletivo e a outra, em expansão, com propriedade privada e de mercado. Solow (2000) argumenta que o sucesso de alguns países asiáticos precisa de algo mais necessário para explicar suas taxas de crescimento, isto é, se os padrões de comportamento (capital social) pertinentes são o que contam para a habilidade dessas sociedades em acumular capital e mobilizar trabalho qualifica-

\footnotetext{
${ }^{2}$ Veblen e Mitchell, considerados fundadores da Escola Institucionalista Americana na década de trinta, tinham como objetivo desenvolver uma análise econômica baseada no estudo das estruturas, regras e comportamentos das instituiçōes. Defendiam ainda que a estrutura política e social de um país pode bloquear ou distorcer processos econômicos normais...(Ver Sandroni (1994) p. 174; 226; 369).
} 
do com rapidez e eficiência, ou apenas uma economia de produção convencional, ainda assim ele não identificou padrão de comportamento para o sucesso das economias asiáticas. Assim, pode-se perceber que, para Solow, o vínculo teórico entre capital social e crescimento econômico pode ocorrer de forma indireta.

Isto leva a uma questão central: Qual o impacto das instituições no desenvolvimento econômico, e por que umas regiōes crescem e outras não?. O capital social, embora muito difícil de mensurar pode ser a resposta desta questão, pois, segundo Putnam (1996), o capital social se fez presente em regiões que obtiveram níveis de crescimento e desenvolvimento maiores do que outras onde as características do capital social se faziam ausentes. O capital social facilita as ações sociais através de características como a organização social, confiança, normas e sistemas jurídicos. As nações e as regiões mais prósperas em um futuro de livre mercado serão aquelas melhor preparadas para formar cidadãos dispostos a trabalhar cooperativamente e organizadas para promover associaçōes voluntárias entre suas instituições. Por isso, tanto a idéia de capital social, quanto à de cooperação, nos últimos anos, têm sido destacadas por organismos internacionais como o Banco Mundial.

Grotaert (1997) ressalta que algumas visões de capital social compartilham de características comuns, sugere que as relações sociais afetam os resultados econômicos e que são afetadas por eles em todos os vínculos das esferas econômica, social e política. Assim as relações entre os agentes econômicos podem melhorar a eficiência das atividades econômicas (formais e informais).

Levando em consideração estes pressupostos, é possível compreender que uma estratégia política de desenvolvimento não pode se ater somente a políticas creditícias, incentivos fiscais ou de investimentos na infra-estrutura. Ela deve, também, procurar manter e ampliar o estoque de capital social em sua comunidade, fortalecendo a auto-organização social, estimulando a prática de soluções colaborativas para problemas comuns, e promovendo a participação e a abertura ao diálogo.

Mas para que haja um progresso real nesse campo, o governo precisa utilizar incentivo, fazer leis e criar instituições inovadoras que fortaleçam esse comportamento e orientem a sociedade no sentido do objetivo comum; ao mesmo tempo o governo precisa procurar, na medida do possível, não intervir diretamente no mercado 
na condição de ator, embora isto possa vir a ser necessário. Deve-se ter a premissa de que o político, o econômico e o social estão interligados em um todo; se a participação política depende da cidadania política, os mesmos critérios abrangentes de cidadania se aplicam às esferas econômica e social. O capital social, portanto, deixa de estar subordinado, exclusivamente, à trajetória histórico-cultural e passa a promover trajetórias diversas de mudança social, gerando oportunidades de desenvolvimento, escala de participação organizada, investimento social e, por conseguinte, sustentabilidade dinâmica do território.

\section{Capital Social como um Elemento Produtivo}

A história de crescimento econômico durante os últimos 50 anos mostra um contraste nos períodos 1950-1974 e 1975-2000. O primeiro era um tempo de prosperidade geral na qual todas as estratégias renderam resultados positivos para países ricos e pobres, com economias abertas e fechadas, localizados em climas temperado e tropical. Havia um relativo bem-estar para todos. O período de vinte anos entre 1974 e 1994, porém, foi desastroso para todos, com exceção dos Tigres Asiáticos; o mundo em desenvolvimento sofreu um colapso de crescimento de vinte anos do qual só emergiu recentemente.

Os teóricos como Romer, Lucas, e Barro endogenizaram, na função de produção, externalidades que causam uma redução dos custos, sendo então amplamente positivas, fazendo gerar rendimentos crescentes. Eles incorporaram novas variáveis aos respectivos modelos de crescimento endógeno: inovações, idéias e tecnologia (ROMER, 1986); capital humano (LUCAS, 1988); despesas publicas (BARRO, 1989, 1990). A partir daí, a literatura econômica recente parece entrar em consenso, ao analisar os fatores propulsores do crescimento econômico, sobre a relação existente entre acumulação de capital humano, investimento em infra-estrutura, progresso tecnológico e um grande número de variáveis capazes de fomentar externalidades sobre o investimento e o crescimento econômico sustentável. Nesse debate, o ponto colocado em foco por uma grande quantidade de pesquisas recentes resume-se em uma questão: por que então a trajetória de crescimento econômico temporal em muito difere entre nações? A partir desta questão, têm surgido mui- 
tos trabalhos baseados na Nova Economia Institucional, onde novas variáveis, e muitas das quais intangiveis, geram adicionais formas de externalidades para explicar a trajetória de crescimento dos países ${ }^{3}$.

Capital social e capital político podem ser endógenos, quando revalorizam o conjunto de recursos de um país ou região e permite a otimização do seu potencial. Alguns estudos, Mauro (1995), Alesina et al.(1996), Alesina (2000), Arraes e Teles (2000), Mo (2001), provaram, através de modelagem econométrica com base na teoria de crescimento endógeno, que a qualidade das instituições tem influ. ência significativa no crescimento econômico. Já Collier (1998) considera que o modo mais fácil de endogenizar capital social é explicar isto em termos dos custos de integração social. Os custos de interação social são as penalidades políticas contra sua formação, e os custos financeiros de comunicação. Conseqüentemente, a um nível altamente agregado, poder-se-ia supor que a ação de capital social é uma função de liberdades civis, densidade de telefone, fragmentação etnolingüística, e densidade de população. Ele ilustra isto em uma regressão para explicar confiança como função de tais variáveis.

Paldan e Svendsem (1999) procuram identificar o capital social como um argumento adicional na função de produção, junto com os fatores convencionais: Capital físico; Capital público (infra-estrutura); Capital Humano e Progresso técnico (Inovação tecnológica). Os modelos de crescimento endógeno trouxeram como elementos importantes para as diferenças de PIB per capita entre os países, elementos como capital humano, o processo de aprender fazendo (learning-by-doing) e os processos relativos à existência de externalidades advindas de inovação tecnológica (efeitos spillover). A inovação seria uma função do estoque de conhecimento da co* munidade, e o Estado atuaria na coordenação dos agentes, principalmente nos países em desenvolvimento em que tal estoque é relativamente reduzido.

Em síntese, capital social é visto como um dispositivo de redução de custos de transação ou monitoramento que poderia ser agre-

\footnotetext{
${ }^{3}$ Sob essa ótica, a perpetuidade de níveis elevados de capital humano, capital fisico e produtividade estāo condicionados à qualidade institucional, de forma que o primeiro passo a ser efetivado em uma política de crescimento sustentável implica-se pela constituição de mecanismos que garantam uma estrutura institucional capaz de prover os fatores causadores e mantenedores do crescimento de forma contínua. Em uma visão simplista, desenvolvimento sustentado seria um crescimento econômico sustentado com uma boa distribuiçāo de renda.
} 
gado como um fator de escala para a produção. Neste caminho, a contribuição da teoria de crescimento endógeno é identificar que fatores de produção atualmente decisivos, como o capital social, o capital humano, o conhecimento, a pesquisa e desenvolvimento, a informação e as instituições, interagem como elementos produtivos e não de forma exógena, como até então era entendido. Por conseguinte, logo se conclui que uma região dotada destes fatores, ou estrategicamente direcionada para desenvolvê-los internamente, teria as melhores condições de atingir um desenvolvimento mais acelerado e equilibrado.

\section{A Escolha dos Modelos}

Variáveis político-institucionais vêm recentemente sendo inseridas por diversos estudos econométricos através de estimações cross-country em painel, a fim de fornecer novas abordagens sobre o diferencial do nível de crescimento entre naçóes. Dentro dessa linha de investigação pode-se discriminar o capital social como uma nova variável explicativa que incorpora as instituições de uma sociedade. Será utilizado um painel de dados com dois períodos para 26 países (1980, 1990), e com três períodos para 20 estados do Brasil (1990, 1994, 1998). Devido a pouca disponibilidade de dados para a variável capital humano, se utilizou informação de 1991 ao invés de 1990, e 1995 ao invés de 1994; assim como dados de gastos primários per capita foram de 1995 ao invés de 1994.

As especificações das variáveis de capital social a serem utilizadas neste estudo apresentam-se na tabela 2. Três critérios básicos foram considerados nas escolhas dos indicadores a serem utilizados nas estimaçōes, e que melhor exprimam qualidade institucional dentro dos padrões que se ajustem e permitam conduzir simulações para o Brasil. O primeiro é a verificação da não-ambigüidade das variáveis com o nível de produto, sendo tal critério amplamente satisfeito pela verificação da existência de um único sentido de tal relação. $O$ segundo critério concerne na necessidade de cada variável apresentar, sob algum aspecto, a natureza de um bem público. Por fim, o terceiro critério é estabelecido pela própria aceitação de tais indicadores como suficientemente capazes de refletir a realidade, pela literatura econômica especializada. 
Duas observaçōes fundamentais devem ser notadas como de essencial importância para a formulação do modelo econométrico. A primeira insere-se no fato de existir uma correlação elevada entre tais variáveis. O segundo ponto decorre da observância de elevada correlação entre as variáveis institucionais e o PIB per capita. Existe um círculo virtuoso entre qualidade institucional e crescimento econômico, de forma que boas instituições favorecem o crescimento, e elevados níveis de renda incentivam a permanência de estabilidade política e de eficiência institucional.

A investigação dos efeitos do capital social sobre o crescimento econômico será realizada através um modelo econométrico de equações simultâneas para países, de forma a ser possível não apenas a verificação da relação entre capital social e crescimento, mas, fundamentalmente, das interações existentes entre capital social e renda per capita, captando assim os efeitos do círculo virtuoso entre tais variáveis, e das interaçōes existentes entre as próprias variáveis. Possibilita-se, então, através deste modelo o teste da endogenidade tanto do crescimento como do capital social conjuntamente. Ressalve-se, porém, que devido à indisponibilidade de dados não foi possível montar um modelo simultâneo para o Brasil.

A escolha do número de variáveis qualitativas para explicar capital social foi tomada a posterior através de um pré-teste, de onde se buscou maximizar a performance do modelo simultâneo através de testes estatísticos. Assim, as equações que visam explicar a qualidade institucional assumem a forma de equaçōes de variáveis dependentes limitada do tipo Probit a serem determinadas conjuntamente. A forma estrutural do modelo que obteve melhor desempenho estatístico para fins de previsão é dada por:

Para países:

$\mathrm{PIBC}=\mathrm{f}_{\mathrm{y}}(\mathrm{H}, \mathrm{I}, \mathrm{S}, \mathrm{G}, \mathrm{GINI}, \mathrm{COMP}, \mathrm{CORR})$

$\mathrm{S}=\mathrm{f}_{\mathrm{S}}(\mathrm{PIBC}, \mathrm{H}, \mathrm{COMP}, \mathrm{CORR})$

$\mathrm{CORR}=\mathrm{f}_{\mathrm{C}}(\mathrm{PIBC}, \mathrm{S}, \mathrm{BUR}, \mathrm{LIB})$

onde,

CORR é igual a " 1 " para valores maiores que 3, e " 0 " caso contrário ${ }^{4}$.

$\mathrm{COMP}=(\mathrm{RLEI}+\mathrm{TPOL}+\mathrm{RG}+\mathrm{MPOL})$

${ }^{4}$ Note-se que o valor 3 representa o ponto médio desta variável (Ver tabela 1). 
Para estados do Brasil:

$\mathrm{PIBC}=\mathrm{f}_{\mathrm{y}}\left(\mathrm{H}, \mathrm{I}, \mathrm{S}^{\prime}, \mathrm{G}, \mathrm{GINI}\right)$

As demais variáveis seguem como especificadas pela tabela 2 . Assim, a primeira equação consiste basicamente no modelo de crescimento endógeno com governo, formulado por Barro (1990), cujas modificações implicam a inserção da variável CORR (corrupção); $\mathrm{S}$ (capital social para países) e S' (capital social para os estados do Brasil), além da variável COMP que representa um índice composto das variáveis: regra de lei (RLEI), militares na política (MPOL), risco de guerra civil (RG), terrorismo político (TP)]. Tais modificações visam à própria identificação do modelo simultâneo, embora tais enxertos sejam amplamente justificados pela teoria, onde a implementação da variável corrupção (CORR) tende a linearizar o efeito da qualidade institucional sobre o crescimento, evitando um resultado inconclusivo (ARRAES e TELLES, 2000).

\section{Base de Dados}

Para a condução das estimações foram direcionados esforços no sentido de coletar e agrupar para os países e estados brasileiros variáveis qualitativamente satisfatórias e capazes de guardar o máximo possível de analogia em relação às utilizadas nas análises crosssections para países. Os dados foram obtidos combinando alguns bancos de dados distintos.

Para os Países:

O primeiro é o Penn World Table mark 5.6 que é um conjunto de dados econômicos em séries temporais que cobre um grande número de países, e as variáveis são expostas em um arranjo comum de preços e moedas correntes que serviram para definir PIB per capita em preços constantes de dólar (PIBC); Gastos do Governo em relação ao PIB (G); Investimentos em relação ao PIB (I). Isto torna possivel comparar reais quantidades diretamente sem os problemas que podem acontecer com dados de contas nacionais diferentes.

O segundo banco de dados é a pesquisa de Valores Mundiais de 45 países levada a efeito entre 1981 e 1990 pela ICPSR - InterUniversity Consortium For Political And Social Research (ICPSR; 2001), de onde é extraída a variável capital social (S) de Knack e Keefer, como o índice de participação cívica e confiança medido 
pelas atitudes das pessoas, aferida em uma escala de 1(nunca justificável) a 10 (sempre justificável), tendo por base a postura das pessoas frente às seguintes situaçōes: (a) reivindicações de benefícios governamentais para os quais não se é o titular; (b) evitar o pagamento de tarifas ao utilizar transporte público; (c) uso de meios escusos para evitar o pagamento de impostos e taxas devidas; (d) disposição em manter um objeto alheio "achado"; (e) deixar de comunicar ao proprietário de um veículo estacionado o dano causado acidentalmente por colisão. Foram feitas pesquisas de opinião, com amostras variando entre 9 mil e 15 mil pessoas em 45 países.

O terceiro banco de dados é oriundo de Easterly (1999), onde estão contidas diversas variáveis institucionais definidas na tabela 2.; Capital Humano $(\mathrm{H})$, calculado como os anos de instrução media na população total acima dos 25 anos de idade, e o índice de Gini (GIND).

Para os Estados Brasileiros:

A primeira fonte de dados é o Anuário Estatístico do Brasil IBGE (2001), com exceção aos dados de 1990 obtidos em Ahmad (2001) com dados sobre o PIB per capita medido em dólares preço paridade consumo pelo world development report; Investimentos (I) que será definido pelo consumo de energia elétrica não residencial percentual, ou seja, consumo de energia geral menos consumo residencial dividido pelo consumo em geral (IBGE ou no site do ministério das minas e energias - MME (2001).

A segunda fonte é o Instituto Universitário de Pesquisas do estado do Rio de Janeiro - IUPERJ (2001) ou no site do Supremo Tribunal Eleitoral - STE (2001) que definiu a variável participação cívica nas eleiçōes estaduais $\left(\mathrm{S}^{\prime}{ }^{3}\right)$. Em terceiro vem o indicador de educação do PNUD $(\mathrm{H})$, medido por uma combinação da taxa de alfabetização de adultos e a taxa combinada de matrícula nos níveis de ensino fundamental, médio e superior, do PNUD (2000) e IPEA (2001). E por último Índice de Gini (GINI) e Despesas Primárias Estaduais per capita a preços constantes de 1999(G), extraídos de Blanco (2001b) ou no site do Ministério da Fazenda que dispõem sobre informações de despesas estaduais (2001).

Uma vez que capital social expressa níveis de confiança, participação cívica e qualidade institucional em uma determinada sociedade, ela foi então definida através do índice de participação cívica e confiança de Knack e Keefer (1997). E, para os estados, tal variável será definida pelo índice de participação em eleições, uma vez que 
"a participação da população no processo político reduz a chance de ter um eleitorado cativo e faz com que a adoção de políticas públicas seja mais imune ao ativismo de grupos de interesse, desestimulando comportamentos do tipo rent-seeking (Blanco; 2001a)" o que permite comparar civismo e confiança institucional nos estados. Segundo Blanco, pode-se esperar ineficiência em estruturas políticas com um elevado grau de fragmentação política, onde comportamentos do tipo pork barril ou logrolling permitem que grupos de interesse exerçam influência sobre a alocação de recursos públicos locais em prejuízo da maioria. Baixa participação da comunidade local pode gerar uma maior vulnerabilidade das esferas inferiores de governo à influência das elites regionais, a comportamentos rent seeking ou simplesmente à própria corrupção. Assim, se as esferas inferiores de governo são mais vulneráveis, as chances de captura das estruturas públicas subnacionais por parte de grupos de interesse constitui um contra-argumento forte à maior eficiência da política das unidades descentralizadas.

Tabela 2: Fonte das Variáveis Institucionais

\begin{tabular}{|c|c|c|c|}
\hline Varid́veis & Simbolo & Descriçāo & Fonto \\
\hline Confiança e Civismo & $S$ & $\begin{array}{l}\text { Indice (1-100); maiores valores representam mais } \\
\text { confiança }\end{array}$ & ICPSR (2001) \\
\hline $\begin{array}{l}\text { Qualidade } \\
\text { Burocrática }\end{array}$ & BUR & $\begin{array}{l}\text { Índice }(1-6) \text {; maiores valores representam menos } \\
\text { burocracia }\end{array}$ & Easterly 11999 \\
\hline Regra à Lei & RLEI & $\begin{array}{l}\text { Índice (1-6); maiores valores representam maior } \\
\text { coesão perante a lei }\end{array}$ & Idem \\
\hline Corrupşão & CORR & $\begin{array}{l}\text { Índice }(1-6) \text {; maiores valores representam menores } \\
\text { níveis de corrupção }\end{array}$ & Idem \\
\hline Direitos Políticos & DPOL & $\begin{array}{l}\text { Indice (1-7); maiores valores representam menores } \\
\text { direitos políticos }\end{array}$ & Idem \\
\hline Militares na Política & MPOL & $\begin{array}{l}\text { Indice }(0-6) \text {; maiores valores indicam menor } \\
\text { participação militar no governo }\end{array}$ & Idem \\
\hline Liberdade Civil & CLIB & $\begin{array}{l}\text { Indice (1)-7); maiores valores representam liberdades } \\
\text { civis reduzidas }\end{array}$ & Idem \\
\hline Terrorismo Político & TPOL & $\begin{array}{l}\text { Indice }(0-6) \text {; menores valores representam maior. } \\
\text { risco de terrorismo }\end{array}$ & Idem \\
\hline Risco de Guerra Civil & RG & $\begin{array}{l}\text { Indice }(0-6) \text {; menores valores representam maior } \\
\text { risco de guerra civil }\end{array}$ & Idem \\
\hline Tensões Étnicas & TR & $\begin{array}{l}\text { Indice (0-6); menores valores representam maior } \\
\text { risco de conflitos étnicos }\end{array}$ & Idem \\
\hline Voto Eleitoral & $S^{\prime}$ & Participação nas eleições estaduais do Brasil. & IUPERJ (2001) \\
\hline
\end{tabular}


Adicionalmente, tomou-se a variável de capital social para o Brasil da forma como definida porque se acredita que o papel dos eleitores na determinação do bem-estar social é tão ou mais importante do que as organizações políticas. Esses eleitores buscam maximizar suas utilidades baseados nas preferências de cada legenda partidária ou na crença e confiabilidade de promessas políticas, e, ao final, decidindo, indiretamente, por situações econômicas, por exemplo, de maiores ou menores níveis de déficit através de escolhas por maiores ou menores níveis de inflação e desemprego, daí segue a escolha por crescimento e desenvolvimento econômico. Desta forma, observa-se a importância do eleitorado na estratégia das políticas que visem a acertos de políticas econômicas. Não obstante, a ampliação do leque de opções políticas oferecidas, por exemplo, pode implicar em um desenvolvimento do eleitorado para avaliação dos programas de governo, bem como da própria gestão das autoridades atuais, uma vez que este aumento da competitividade do sistema politico pode atuar como um fator disciplinador de determinada política econômica no sentido de as decisões do governo serem mais transparentes e as chances de punição através do voto passarem a ser maior.

Ao se inspecionar a variável de participação de eleitores nas eleições estaduais (S') como proxy para capital social, constata-se que, ao longo do período analisado, e em todas as regióes brasileiras, os níveis médios de participaçōes nas eleições aumentaram, tendo as regiōes menos desenvolvidas apresentado as maiores variações percentuais de participação; porquanto a média dos estados da Região Norte variou em 52\%, a Região Centro-Oeste em $46 \%$ e a Região Nordeste em 28\%. Por outro lado, o fato de a Região Sul ter aumentado o índice de participação em $20 \%$, explica-se por a mesma deter o maior índice absoluto de capital social, medido por esta participação política, em relação às outras regiões. Ressalve-se, todavia, que, em alguns estados isolados, o aumento na participação política foi desprezível, se comparados a outros estados da mesma região. Por exemplo, no Nordeste, a variação percentual no índice de participação na Bahia, Ceará e Paraíba foi menos de $3 \%$, em contraposição a Alagoas que foi de 71\%. Já na Região Sul, o Paraná variou em 7\%, enquanto no Rio Grande do Sul tal variaçāo foi de $35 \%$. Nestes casos isolados pode estar funcionando um poder de punição extrema por parte dos eleitores. 


\section{Resultados}

Os modelos de crescimento endógeno formulam que variaçōes em políticas educacionais, tecnológicas, fiscais e de comércio exterior e no grau de distribuição de renda conduzem a efeitos permanentes sobre o produto per capita. Embora as estimaçōes para os estados apresentem resultados inferiores aos encontrados para os países, a análise implementada demonstra claramente uma forte relação entre as variáveis explicativas e o comportamento do PIB per capita de longo-prazo, o que evidencia a veracidade da endogenidade das variáveis institucionais. Outras variáveis institucionais, que não apenas as aqui apresentadas, foram testadas, mas omitidas dos resultados por não indicarem qualquer relevância, tais como 6 índice de direitos políticos e o índice de fragmentação etnolingüústica.

A tabela 3 apresenta os resultados do modelo estrutural (1), onde as equações foram estimadas pelo método dos mínimos quadrados de dois estágios. O ajustamento satisfatório obtido nas três equações permite inferir algumas conclusões básicas, além de prover confiança e eficácia nas previsōes e simulaçōes daí decorrentes. Em primeiro lugar, confirma-se a endogenidade do crescimento econômico em uma amostra de países com características econômicas heterogêneas. Em segundo lugar, há simultaneidade entre os fatores qualitativo-institucionais e a determinação do crescimento. Em terceiro lugar, o crescimento econômico é condição necessária para o aumento da eficiência institucional. Assim, a tabela 3 apresenta os resultados para os países e a tabela 4, para os estados brasileiros.

Os resultados da tabela 3 corroboram a hipótese de que variáveis institucionais, assim como o capital social, ao se mostrarem significantes, indicam que estas contribuem de forma incisiva na formação de vantagens comparativas para os níveis de produtividade, conseqüentemente no crescimento e desenvolvimento econômico dos países. 
Tabela 3: Estimativas do Modelo (1) - Países.

\begin{tabular}{|c|c|c|c|}
\hline $\begin{array}{c}\text { Variáveis } \\
\text { Explicativas }\end{array}$ & \multicolumn{3}{|c|}{ Equações } \\
\hline & PIBC & S & CORR \\
\hline C & $-2827,00$ & 11,51 & $-1,32$ \\
$H$ & $329,97^{*}$ & $0,35^{*}$ & \\
$I$ & 30,14 & & \\
G & $-78,0$ & & $-0,083^{*}$ \\
S & $56,95^{*}$ & & \\
GIN1 & $-38,39$ & $1,08^{*}$ & \\
CORR & $2422,03^{*}$ & & $0,34^{*}$ \\
COMP & $411,85^{*}$ & & $-0,31$ \\
BUR & & & 0,00017 \\
LIB & & $0,0016^{*}$ & $-2 e ̈)^{*}$ \\
PIBC & & $-2 e ̈)^{*}$ & \\
R2 & 0,83 & & \\
\hline
\end{tabular}

Notas:- $\left.{ }^{*}\right)$ significância a, no máximo, $10 \%$; $(-2 e ̈)$ refere-se à estatística $\div^{2}$ relativa ao teste de razão de máxima verossimilhança.

Tabela 4: Estimativas do Modelo (2) - Estados do Brasil.

\begin{tabular}{c|c|c|c|c|c|c|c}
\hline & \multicolumn{6}{|c|}{ Variáveis } & \\
\hline & $\mathrm{C}$ & $\mathrm{H}$ & $\mathrm{I}$ & $\mathrm{G}$ & $\mathrm{GINI}$ & $\mathrm{S}^{\prime}$ & $\mathrm{R} 2$ \\
\hline Eq. PIBC & $-13436,2^{*}$ & $13,1^{*}$ & $2,4 \mathrm{E}-06$ & $1,76^{*}$ & 62,28 & $4,96^{*}$ & 0,58 \\
\hline
\end{tabular}

Nota: (") significância a, no máximo, $10 \%$.

As estimativas mostradas nas tabelas 3 e 4 denotam sinais das variáveis correspondentes de acordo com expectativas teóricas que compõem as respectivas equações para países e estados do Brasil, respectivamente. A fim de verificar as carências produtivas de cada país analisado e de cada estado do Brasil foram utilizados os modelos estimados objetivando realizar simulações comparativas entre o país líder, no caso os Estados Unidos, e os demais países; e no caso dos estados, entre estes e o estado líder, o Distrito Federal, alcançando-se os resultados preditos pelas tabelas 5 e 6 . 


\subsection{Cenários e Simulações para os Modelos (1) e (2)}

A segunda coluna das tabelas 5 e 6 apresenta a relação percentual entre o PIB per capita do país líder (Estados Unidos) ou estado líder (Distrito Federal) para os países ou estados, respectivamente, enquanto as demais colunas estimam qual seria essa relação caso determinado país ou estado relacionado tivesse o estoque do fator listado igual ao do país ou estado líder. Como exemplo, considere o caso brasileiro, cujo PIB per capita representava $22,39 \%$ do PIB per capita americano em 1990. É importante ressaltar, todavia, que alguns resultados refletem de forma convincente as carências e necessidades de cada país, o mesmo ocorrendo com os estados analisados.

Há fortes evidências de que o grau de desenvolvimento institucional afeta negativamente ou positivamente a produtividade dos fatores econômicos, implicando a diminuição ou aumento da renda per capita de um país. Para o Brasil, caso tivesse a qualidade institucional e o nível de capital social que vigoram em países desenvolvidos como Canadá e países da Europa Setentrional, o país melhoria substancialmente seu nível de PIB per capita. No caso das economias desenvolvidas, como Canadá, Suíça, Dinamarca, Finlândia, Suécia, e Noruega, essa diferença percentual em relação ao Brasil é elevada; por exemplo, se o Brasil tivesse a qualidade institucional da Noruega, seu PIB per capita teria tido, em média, um adicional de $80 \%$ de acordo com a simulação mostrada na tabela 7 adiante. Mas, no caso de economias pobres ou em desenvolvimento, essa diferença em sentido oposto é menor, uma vez que são menores os diferenciais em termos de corrupção e de qualidade institucional, exceção feita ao capital social, em que o Brasil apresenta indicadores comparáveis aos de países africanos. Caso a dotação institucional do Brasil se igualasse à da Índia, por exemplo, seu PIB per capita teria decrescido $62 \%$. Fica claro, todavia, o forte efeito elástico de tais variáveis sobre o nível de renda per capita dos países. 
Tabela 5: Simulações do PIB per Capita dos Estados Brasileiros - 1998 - (\%)

\begin{tabular}{c|cccccc}
\hline Estados & PIBC & GINI & H & 1 & S' & G \\
\hline Maranhão & 10,24 & 96,83 & 77,90 & 143,34 & 200,00 & 10,72 \\
Piauí & 12,36 & 95,24 & 77,03 & 88,80 & 157,42 & 17,09 \\
Ceará & 20,38 & 98,41 & 79,63 & 107,45 & 150,32 & 20,95 \\
R. G. do Norte & 19,78 & 95,24 & 80,50 & 120,87 & 122,58 & 32,89 \\
Paraíba & 16,74 & 101,59 & 80,07 & 112,85 & 158,71 & 20,28 \\
Pernambuco & 24,98 & 95,24 & 82,56 & 108,26 & 165,16 & 27,02 \\
Alagoas & 17,38 & 100,00 & 85,59 & 134,77 & 181,94 & 15,25 \\
Sergipe & 22,74 & 98,41 & 85,48 & 127,83 & 139,35 & 40,30 \\
Bahia & 23,61 & 95,24 & 82,67 & 133,00 & 205,16 & 29,16 \\
Minas Gerais & 40,05 & 90,48 & 92,31 & 131,11 & 128,39 & 34,35 \\
Espírito Santo & 45,20 & 93,65 & 91,12 & 133,19 & 140,65 & 48,51 \\
Rio de Janeiro & 55,91 & 92,06 & 97,18 & 11,25 & 130,32 & 38,46 \\
São Paulo & 70,43 & 85,71 & 97,83 & 119,49 & 106,45 & 44,24 \\
Paraná & 47,49 & 90,48 & 95,12 & 121,58 & 136,13 & 39,59 \\
Santa Catarina & 48,75 & 84,13 & 98,16 & 124,79 & 105,16 & 29,87 \\
R. G. do Sul & 55,23 & 88,89 & 96,97 & 117,27 & 96,13 & 52,24 \\
M. G. do Sul & 38,88 & 85,71 & 92,52 & 108,16 & 133,55 & 38,25 \\
Mato Grosso & 32,03 & 92,06 & 94,15 & 94,60 & 187,10 & 39,38 \\
Goiás & 28,27 & 92,06 & 91,66 & 105,53 & 132,90 & 29,16 \\
Distrito Federal & 100,00 & 100,00 & 100,00 & 100,00 & 100,00 & 100,00 \\
\hline
\end{tabular}

Nota: Valores mais baixos para H, I, G, dos estados em relação ao Distrito Federal implicam despesas mais baixas em relação a estas variáveis, enquanto o Índice de GINI valores mais baixos representam uma distribuição melhor e para Abstençāo ( $\left.S^{\prime}\right)$ valores maiores implicam em baixa participação cívica.

Parece aceitável que nunca seremos um Canadá ou um país do Norte da Europa, dadas as especificidades destes. Tais dados evidenciam que um ambiente institucional de qualidade, aliado a um bom nivel de capital social, tem conseqüencias diretas sobre a performance econômica de um modo geral, que podem por até em risco a democracia, que é a principal instituição no combate a este fenômeno.

Países com piores distribuições de renda tiveram um comportamento expansivo por parte do setor público, embora o coeficiente de impacto da distribuição de renda sobre o comportamento do setor público seja muito pequeno. Combinada com as variáveis institucionais e de capital social, por exemplo, teria seu coeficiente de impacto reduzido ou ampliado em função desta combinação. 
Outrossim, regimes mais democráticos, à medida que possibilitam posições de descontentamento com a má utilização dos recursos públicos, tendem a diminuir o nível de burocracia da economia. Como era de se esperar, os países industrializados atingem performance elevada quanto à qualidade institucional, e o conseqüente efeito direto sobre crescimento/desenvolvimento econômico, o que está de acordo com a hipótese formulada por Lucas (2002). Já países que denotam elevada conturbação político-institucional, por exemplo, Nigéria, detêm elevada chance de serem ineficientes e, por conseguinte, gerarem baixo crescimento do PIB, e de estarem confinados a uma armadilha da pobreza. Tais conclusões emanam da acurácia do modelo estrutural e sua elevada confiabilidade para fins de previsão.

Tabela 6: Simulações do PIB per Capita dos Países - 1990 - (\%)

\begin{tabular}{|c|c|c|c|c|c|c|c|c|}
\hline \multirow{2}{*}{ Palsos } & \multicolumn{8}{|c|}{ Varidveis } \\
\hline & PPBC & $\mathrm{H}$ & 1 & G & 5 & COMP & CORR & GNI \\
\hline EUA & 100,00 & 100,00 & 100,00 & 100,00 & 100,00 & 100,00 & 100,00 & 100,00 \\
\hline Canadá & 95,12 & 87,97 & 130,05 & 93,13 & 109,25 & 109,09 & 83,33 & 121,75 \\
\hline Norvega & 82,54 & 81,34 & 104,93 & 128,24 & 134,80 & 109,09 & 83,33 & 128,55 \\
\hline Suécia & 81,77 & 32,00 & 120,69 & 170,23 & 125,77 & 104,55 & 83,33 & 128,68 \\
\hline Dinamarca & 77,04 & 87,65 & 104,93 & 154,96 & 123,35 & 109,09 & 83,33 & 127,85 \\
\hline Finlândia & 77,87 & 80,52 & 162,07 & 120,61 & 125,99 & 109,09 & 83,33 & 157,79 \\
\hline Suíça & 91,42 & 80,15 & 171,92 & 72,52 & 101,76 & 109,09 & 83,33 & 99,42 \\
\hline Áustria & 70,32 & 56,35 & 130,05 & 96,95 & 70,04 & 109,09 & 100,00 & 117,59 \\
\hline Halanda & 72,17 & 37,48 & 109,85 & 89,31 & 101,76 & 109,09 & 83,33 & 127,41 \\
\hline França & 77,01 & 55,34 & 134,98 & 112,21 & 54,63 & 95,45 & 100,00 & 110,84 \\
\hline Reino Unido & 73,21 & 73,37 & 91,13 & 124,43 & 97,80 & 90,91 & 100,00 & 114,86 \\
\hline Bélgica & 73,29 & 77,64 & 122,66 & 83,97 & 66,52 & 104,55 & 100,00 & 137,78 \\
\hline Irlanda & 51,37 & 31,81 & 113,79 & 90,08 & 88,55 & 100,00 & 100,00 & 95,52 \\
\hline Itália & 69,17 & 67,94 & 121,67 & 88,55 & 57,93 & 95,45 & 125,00 & 131,29 \\
\hline Espanha & 53,08 & 42,04 & 143,35 & 98,47 & 75,99 & 77,27 & 125,00 & $|43,4|$ \\
\hline Portugal & 41,42 & 88,08 & 80,30 & 170,23 & 47,14 & 86,36 & 100,00 & 107,88 \\
\hline Turquia & 20,72 & 27,95 & 100,99 & 85,50 & 22,03 & 50,00 & 250,00 & 82,57 \\
\hline Austrália & 80,01 & 86,88 & 117,73 & 98,47 & 105,29 & 109,09 & 100,00 & 89,06 \\
\hline Japão & 79,38 & 53,25 & 190,64 & 58,78 & 89,87 & 100,00 & 100,00 & 106,16 \\
\hline Coréia do Sull & 36,96 & 71,76 & 181,77 & 64,89 & 83,70 & 68,18 & 250,00 & 106,29 \\
\hline India & 7,00 & 25,84 & 78,82 & 230,53 & 75,55 & 31,82 & 250,00 & 117,49 \\
\hline Argentina & 26,07 & 56,64 & 56,65 & 29,77 & 59,47 & 72,73 & 125,00 & 78,08 \\
\hline Brasil & 22,39 & 29,57 & 74,88 & 103,82 & 74,76 & 81,82 & 125,00 & 62,34 \\
\hline Chile & 24,03 & 54,72 & 130,05 & 125,95 & 50,00 & 68,18 & 166,67 & 70,98 \\
\hline México & 32,28 & 71,75 & $73 ; 89$ & 68,70 & 39,01 & 77,27 & 166,67 & 73,86 \\
\hline Nigeria & 5,51 & 72,72 & 39,41 & 177,10 & 50,44 & 36,36 & 250,00 & 94,5 \\
\hline
\end{tabular}

Nota: Valores mais baixos para H, I, dos países em relação aos Estados Unidos implicam despesas mais baixas em relação a estas variáveis, o Índice de GINI, COMP, S, com valores maiores representam uma distribuição melhor e em uma melhor qualidade institucional; para CORR valores maiores implicam menores índices de corrupção, e para $G$ nada se pode afirmar, pois as despesas de cada país devem considerar eficiência e qualidade das políticas públicas. 
Tabela 7: Simulaçōes dos Efeitos das Variáveis Institucionais de Outros Países Sobre PIB per Capita do Brasil - 1990

\begin{tabular}{c|c|c|c|c|c}
\hline Palses & Efoitos (\%) & Palses & Efoitos $(\boldsymbol{\%})$ & Palses & Efoitos (\%) \\
\hline Brasil & 100,0 & Austrália & 156,0 & Portugal & 128.4 \\
Canadá & 175,0 & Suíça & 174.1 & Espanha & 109.1 \\
Dinamarca & 178,0 & Reino Unido & 141.7 & Argentina & 102.6 \\
Finlândia & 178.9 & EUA & 148.6 & Chile & 78.7 \\
Noruega & 180.7 & França & 136.5 & México & 82.9 \\
Suécia & 175.7 & Irlanda & 146.3 & Índia & 39.6 \\
Áustria & 148.9 & Irólia & 118.2 & Turquia & 41.6 \\
Holanda & 174.1 & Japäo & 146.5 & Nigéria & 37.7 \\
\hline
\end{tabular}

Esses resultados demonstram também que um baixo nível de crescimento e desenvolvimento econômico implica necessariamente também em baixo nível de qualidade institucional, ficando assim comprovada a seguinte simultaneidade de causa e efeito:

Qualidade Institucional $\Leftrightarrow$ Crescimento/Desenvolvimento Econômico

\section{Conclusões}

Ao longo deste trabalho sustentou-se que capital social, como um elemento institucional especifico, pode explicar o atraso relativo de países ou regiões. Instituições ruins restringiriam as perspectivas de crescimento, no longo prazo, dos países e regiões, já o capital social seria o elo de ligação entre a desigualdade e o atraso econômico.

A hipótese de que qualidade institucional e crescimento econômico são faces de uma mesma moeda foi aceita satisfatoriamente neste artigo. Das estimações e simulações pode-se inferir que a qualidade institucional afeta não apenas o nível de crescimento de longo prazo, como também indica que o primeiro passo a ser efetivado em uma política de crescimento sustentável dá-se pela constituição de mecanismos eficazes que garantam uma estrutura institucional capaz de prover os fatores causadores e mantenedores do crescimento de forma contínua.

Estimativas confiáveis permitiram previsões acuradas para vários países. No caso do Brasil, as estimativas demonstram que o país encontra-se a uma longa distância do estado institucional dos países desenvolvidos. 
Está claro também que capital social é um fator deveras relevante para explicar as variações de crescimento econômico entre países. Quando a variável está incorporada em um modelo de crescimento, é um predito altamente significante de crescimento em um painel diverso de países, e na presença de várias variáveis de controle. Além disso, estes resultados não são dependentes do fato de um país ter ou não um governo democrático.

Capital social é, em última instância, um conjunto de valores sociais, e quanto mais completo a quantidade de valores para tal conjunto, melhor desempenhará seu papel-chave de contribuir para explicar as variações do desempenho econômico, de sorte que não pode ser ignorado em qualquer modelo adequado de crescimento econômico, principalmente quando este se propõe a lançar previsões de longo prazo.

Nota sobre $S^{\prime}$ : Adicionalmente, papel dos eleitores na determinação do bem-estar social é certamente muito mais importante que o dos partidos políticos. Estes indivíduos buscarão maximizar sua utilidade baseados nas preferências de cada legenda partidária e decidirão indiretamente por uma situação de maiores ou menores níveis de déficit através de escolhas por maiores ou menores níveis de inflação e desemprego. A questão é que a busca por uma situação de maior bem-estar pode implicar em uma pior situação econômica no que se refere à existência de déficits nas contas públicas, principalmente quando se trata de gastos com pessoal e emprego, negligenciando-se os investimentos.

O fato de uma determinada administraçāo pública preferir transferir para gerações futuras o ônus do ajuste fiscal, não convencendo os grupos sociais aliados da necessidade de se reduzir ou eliminar o déficit público, implicará uma política econômica ineficiente no tocante ao déficit público. Desta forma, observa-se a importância do eleitorado na estratégia das políticas que visem à estabilização fiscal. Não obstante, a ampliação do leque de opçōes políticas oferecidas, por exemplo, pode implicar em um desenvolvimento do eleitorado para avaliaçāo dos programas de governo, bem como da própria gestão das autoridades atuais, uma vez que este aumento da competitividade do sistema político pode atuar como um fator disciplinador da política fiscal no sentido de que as decisōes de gasto do governo são mais transparentes e as chances de punição através do voto passam a ser maiores.

\section{Referências Bibliográficas}

ABRAMOVITZ, Moses. Catching up, Forging Ahead, and Falling Behind. Journal of Economic History. v. XLVI, p. 385-406, 1986.

ABRAMOVITZ, Moses; DAVID, Paul. Convergence and Deferred Catch up: Productivity Leadership and the American Exceptionalism. In: Landau, Ralph, Taylor, Thimoty, Wright, Gavin (Eds.), The Mosaic of Economic Growth. Stanford University Press, Stanford, 1996. 
ACEMOGLU, D.; JONHSON, S.; ROBINSON, J.. The Colonial Origins of Comparative Development: An Empirical Investigation. Cambridge: NBER Paper $\mathrm{n}^{\circ}$ 7771, 2000.AHMAD, S. Dados do World Development Report. World Bank, Washington, 2001.

ALESINA, A. et al. Political Instability and Economic Growth. Journal of Economic Growth, v.1, p. 189-211, 1996.

ARRAES, R., TELES, V.K. Fatores Institucionaise Crescimento Econômico: Cenários para o Brasil e Países Selecionados. Anais do XXVIII Encontro Nacional de Economia da ANPEC. [CD-ROM], Campinas, p. 22, 2000.

BARRO, Robert. A Cross-Country Study of Growth, Saving and Government. Cambridge: National Bureau of Economic Research Working Paper 2855, 1989.

. Government Spending in a Simple Model of Endogenous Growth. Joumal of Political Economy. v. 98 n. 5, 1990.

BARRO, Robert. Economic Growth in a Cross Section of Countries. Quarterly Journal of Economics, v. 106, p. 407-444. 1991.

BLANCO, F. O Comportamento Fiscal dos Estados Brasileiros e seus Determinantes Políticos. Revista da ANPECn. 1 - janeiro/junho 2001a.

. Efeitos das Despesas Públicas dos Estados Sobre Indicadores Sócio-Econômicos Estaduais. ANPEC - Encontro Nacional de Economia; Salvador-Ba, $2001 \mathrm{~b}$.

COLE, Harold L. et al. Social Norms, Savings Behavior, and Growth. Journal of Political Economy, v. C, p. 1092-1125, 1992.

COLEMAN, J. Foundations of Social Theory. Cambridge, Mass: Harvard University, 1990.

Social Capital in the Creation of Human Capital. American Joumal of

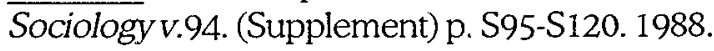

COLLIER, P. Social Capital and Poverty. Washington, DC: The World Bank (mimeo), 1998.

EASTERLY, William. Life During Growth Joumal of Economic Growth, v. 4, n. 3, p. 239-275, 1999.

Can institutions resolve ethnic conflict?; World Bank: February, 2000.

EASTERLY, William. Explaining Miracles: Growth Regressions Meet the Gang of Four. In: Ito, Takatoshi; Krueger, Anne (eds). Growth Theories in Light of East Asia Experience. University of Chicago Press, Chicago, 1995.

FGV. Revista Conjuntura Econômica. Varias edições. 
GROOTAERT, C. Social Capital: The Missing Link? in Expanding the Measure of Wealth: Indicators of Environmentally Sustainable Development. Environmentally Sustainable Development Studies and Monographs Series N. 7. Washington, DC: World Bank, 1997.

HELLIWEL, J.; PUTNAM, R.. Education And Social Capital. Cambridge: NBER Paper n. 7121, 1996.

INGLEHART, Ronald. Post modernization Brings Declining Respect For Authority But Rising Support For Democracy. Forthcoming in Pippa Norris (ed.), Critical Citizens: Global Support for Democratic Government. Oxford University Press. Oxford: 1999.

IBGE. Anuário Estatístico do Brasil. Varias edições.

IPEA. Instituto de Pesquisas Econômicas Aplicadas. Brasília, [Online] Disponível na Internet via WWW. URL: http://www.ipea.gov.br; extraído em 20.11.2001.

IUPERJ. Instituto Universitário de Pesquisa do Rio de Janeiro. [Online] Disponível na Internet via WWW. URL: http://www.iuperj.br; extraído em 20.11.2001.

KNACK, Stephen. Social Capital, growth and poverty: a survey of cross-country evidence. The World Bank Social Development Family Environmentally and Socially Sustainable Development Network, April, 1999.

KNACK, S.; KEEFER, P. Does social capital have an economic payoff? A crosscountry investigation. Quarterly Journal of Economics, v. 112, n. 4, p. 1251-1288, 1997.

LUCAS, R.E. "On the mechanics of economic development", Journal of Monetary Economics, v. 22, p. 3-42, 1988.

.The Industrial Revolution: Past and Future. In: Lucas, R., org., "Lectures on Economic Growth" Harvard University Press, Cambridge, p. 109-188, 2002.

. Why doesn't capital flow from rich to poor countries? American Economic Review, v. 80, n. 2, p. 92-96. 1990.

MANKIW, G.; ROMER, D.; WEIL, D. "A contribution to the empirics of economic growth", Quarterly Joumal of Economics, 107, 407-437, 1992.

MAURO, Paolo. Corruption and Growth. Quarterly Journal of Economicsv. 110, p. 681-712, August 1995.

MME. Ministério das Minas e Energias. [on-line] disponível na Internet via WWW. URL: http://www.mme.gov.br. 2001.

MO, Pak Hung. Corruption and Growth. Journal of Comparative Economics, v. 29, p. 66-79, 2001.

MONASTÉRIO, L. M.. Capital social e Economia: antecedentes e perspectivas. V Encontro de Economia Política em Fortaleza, Junho de 2000a. 
- Capital Social e Crescimento Econômico: Mecanismos. III Encontro de

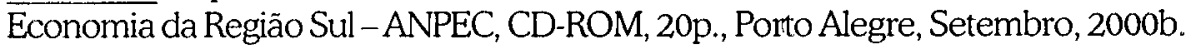

. Capital social e grupos de interesse: uma reflexão no âmbito da economia regional. In: XXVII Encontro Nacional de Economia, Anais. Belém: ANPEC, 1999.

Putnam no Pampa: capital social e a metade sul do Rio Grande do Sul. II Encontro da Sociedade Brasileira de Nova Economia Institucional. Unicamp, Campinas: Março de 2001.

. Estagnação econômica e esclerose institucional: as abordagens de Olson e de Veblen. I Seminário Nacional de Nova Economia Institucional, São Paulo, 1998.

MORAES, Aod C. O Conceito de Eficiência na Nova Economia Institucional. III Encontro de Economia da Região Sul - ANPEC., CD-ROM, 20p., Porto Alegre, 2000.

NORTH, Douglas. Institutions, Institutional Change, and Economic Performance. New York: Cambridge University, 1990.

OECD. Employment Outlook, Paris: OECD, 1996.

PALDAM, Martin;SVENDSEN, Gert T. Is social capital an effective smoke condenser?: an essay on a concept linking the social sciences. W. Paper n. 11, World Bank, May 1999.

PNUD. Atlas do Desenvolvimento Humano no Brasil (cd-rom encartado em PNUD), 2000.

PUTNAM, R. Bowling Alone: the collapse and revival of American community. New York: Simon E Schuster; 2000.

. Comunidade e democracia: a experiência da Itália moderna. Rio de Janeiro: FGV, 1996.

ROMER, P. Increasing Returns and Long Run Growth. Journal of Political Economy, 97, 1986.

SANDRONI, Paulo. Novo Dicionário de Economia. Ed. Best Seller. São Paulo, 1994. SOLOW, R. Notes on Social Capital and Economic Performance. In: DASGUPTA, Partha, SERALGEDIN, Ismail. Social Capital: A Multifaceted Perspective. p.6-12, Washington, D.C: World Bank, 2000.

STE. Supremo Tribunal Eleitoral. Brasilia; [on-line] disponivel na Internet via WWW. URL: http://www.ste.gov.br.; 2001.

STN. Secretaria do Tesouro Nacional. Brasilia; [on-line] disponível na Internet via WWW. URL: http://www.stn.fazenda.gov.br; 2001. 
WHITELY, Paul. Economic Growth and Social Capital; Sheffield; na Internet via WWW. URL: http://www.shef.ac.uk/uni/academic/N-Q/perc/Polpaps/Pp6.html. 2001.

WORLD BANK. The Initiative on Defining, Monitoring and Measuring Social Capital: Overview and Program Description. Social Capital Initiative, Paper N.1. Washington, D.C: World Bank, 1998a.

.The Initiative on Defining, Monitoring and Measuring Social Capital: Text of Proposals Approved for Funding. Social Capital Initiative, Paper N.2. Washington, D.C: World Bank, 1998b.

. Relatório Sobre ODesenvolvimento Mundial 2000/2001 - Luta Contra A Pobreza. Washington, D.C: World Bank, 2001.http://www.worldbank.org. 